\title{
Effect of Ethanolic Extract of Crataeva nurvala Bark on lodothyronine Deiodinases Oxidative Stress and Thyroid Histology in 6-Propyl-2-Thiouracil Induced Hypothyroid Mice Model
}

\author{
Arshvir Kaur*1 and Santosh Kumar Verma ${ }^{2}$ \\ ${ }^{1}$ Department of Pharmacology, Delhi Institute of Pharmaceutical \\ Sciences and Research, New Delhi, India \\ ${ }^{2}$ Department of Pharmacology, Faculty of Pharmaceutical Sciences, \\ Motherhood University, Bhagwanpur, Karaundi, Uttarakhand, India
}

\section{ABSTRACT}

In Ayurveda, "Galaganda" (enlarged thyroid gland) occur due to disequilibrium among three doshas i.e. Vata, Pitta and Kapha leading to hormonal imbalance (Ojus). Levothyroxine ( $\left.\mathrm{LT}_{4}\right)$ is the standard replacement therapy in hypothyroidism, clinically that offers a similar life quality, whereas the psychological adverse effects and its pharmacokinetic interactions questions its use. In ancient literature, Crataeva nurvala (CN) Buch-Ham, (family, Capparidaceae) or Varuna is known to regulate, tridoshas and other thyroid problems. A preclinical study confirms its thyrotropic and antihyper-chloesteronemic effects but its mechanism via iodothyronine deiodinases, effect on thyroid histopathology and physiological parameters need to be explored. The levels of Total thyroxine $\left(\mathrm{T}_{4}\right)$, triidothyronine $\left(\mathrm{T}_{3}\right), \mathrm{T}_{3} / \mathrm{T}_{3}$ ratio, oxidative stress (reduced glutathione (GSH) and lipid peroxidation) and physiological parameters were studied. The Swiss albino female adult mice were randomly divided into four groups $(\mathrm{n}=6)$ i.e. Group I to IV who were made hypothyroid using 6-propyl-2-thiouracil (PTU) for first 15 days and then treated with vehicle only, $\mathrm{LT}_{4}(14.56 \mu \mathrm{g} / \mathrm{kg}$ ), CN $400 \mathrm{mg} / \mathrm{kg}$ and CN $600 \mathrm{mg} / \mathrm{kg}$ (p.o.) for another 15 days respectively. The variation in the biochemical parameters was recorded on Day $30^{\text {th }}$. Under hypothyroid conditions, $\mathrm{T}_{3} / \mathrm{T}_{4}$ ratio in comparison with the standard i.e. $\mathrm{LT}_{4}$, depicts significant iodothyronine deiodinases stimulatory activity of CN extract, with significant consumption of GSH for combating raised MDA levels thus possessing the thyroprotective effect, along with maintaining thyroid histoarchitecture.

KEY WORDS: HYPOTHYROIDISM, LEVOTHYROXINE, CRATAEVA NURVALA, IODOTHYRONINE DEIODINASES, THYROXINE.

\section{INTRODUCTION}

Levothyroxine (LT4) is the standard replacement therapy in hypothyroidism, clinically that offers a similar life quality, whereas the psychological well being is compromised (Garber et al., 2012; Petersen et al., 1990; Saravanan et al., 2002). Also, many physiological and pathological conditions can impair $\mathrm{LT}_{4}$ absorption such

Biosc Biotech Res Comm P-ISSN: 0974-6455 E-ISSN: 2321-4007

\section{rossef}

Identifiers and Pagination

Year: 2021 Vol: 14 No (9) Special Issue

Pages: 158-163

This is an open access article under Creative

Commons License Attribn 4.0 Intl (CC-BY).

DOI: $h t t p: / / d x$.doi.org/10.21786/bbrc/14.9.30 as patient factors (compliance), certain foods (e.g. Grapes, coffee, soyabean, papaya etc.), age factor, drugs (e.g. Antacids containing aluminium, sucralfate, proton pump inhibitors, rifampicin, antiepileptics, etc.) gastrointestinal diseases (e.g. Helicobacter pylori infection, celiac disease). The overtreatment with $\mathrm{LT}_{4}$ results in TSH suppression, cardiovascular health risk, high risk of skeletal fracture, especially postmenopausal women, however, short administration of $\mathrm{LT}_{4}$ does not compromise bone density but possible affective disturbances are seen (Razvi et al., 2012; Schneider et al., 2012; Botella-Carretero et al., 2003).

In Ayurveda, thyroid disorders are discussed under the term "Galaganda" (enlarged thyroid gland). As per Ayurveda, Varuna leaves, stem bark and root bark
Article Information

Received: 24 $4^{\text {th }}$ May 2021

Accepted after revision: $14^{\text {th }}$ July 2021 
are reported to be used in maintaining equilibrium among three doshas (bodily humours) Vata, Pitta and Kapha, whose imbalance can lead to Ojus (hormonal imbalance), most commonly thyroid disorders (Kaur et al., 2016). Crataeva nurvala Buch-Ham (CN), belonging to the family, Capparidaceae, synonymously called as C. magna (Lour.) DC., C. religiosa Hook. F and Varuna (Khare, 2007). It is reported to possess analgesic, neuroprotective, antiarthiritic, anticancer, antidiabetic, cardioprotective, anti-inflammatory, antioxidant, hepatoprotective, nephroprotective activities (Khattar \&t Wal, 2012). Traditionally its use is reported in treating cancer, paralysis, thyroid problems etc. (Narayana \&t Subhose, 2005).

Pre-clinically it has been demonstrated that $\mathrm{CN}$ bark extract can elevate free thyroxine (FT4) and lower the raised cholesterol levels (Kaur et al. 2017). However the mechanism behind $\mathrm{CN}$ thyrotropic activity, mainly via iodothyronine deiodinases, effect on thyroid gland histology and physiological parameters in hypothyroid mice needs to be explored in comparison with its per se effects in normal healthy mice (Kaur et al. 2018). So, this study is aimed to evaluate the mechanism of thyroprotective activity and effects on thyroid histopathology and physiological parameters in hypothyroid mice, whose thyroid status was altered by using (6-propyl-2-thiouracil) PTU, as an inducing agent, that selectively inhibits iodothyronine deiodinases type I (DI01) mediated thyroxine $\left(\mathrm{T}_{4}\right)$ conversion to Triidothyronine $\left(\mathrm{T}_{3}\right)$ at thyroid gland and at periphery over iodothyronine deiodinases type II ( $\mathrm{DIO}_{2}$ ) and results in disruption of thyroid histology with physiological changes (Bianco et al. 2002; Moriyama et al., 2007).

\section{MATERIAL AND METHODS}

Chemicals: 6-Propyl-2-thiouracil (PTU) was procured from Sigma-Aldrich Chemie GmbH and Levothyroxine Sodium tablets (Eltroxin) were purchased from the local vendor. All other reagents used for analysis, extraction and phytochemical screening were of analytical grade.

Table 1. Biochemical changes in thyroid hormones and oxidative stress parameters in thyroid tissue and serum of PTU induced hypothyroid and CN treated mice.

\begin{tabular}{|c|c|c|c|c|}
\hline Groups & & & & \\
\hline Parameters & $\mathrm{PTU}+\mathrm{VEH}$ & PTU+STD & PTU+CN 400 & PTU+CN 600 \\
\hline Total thyroxine $\left(\mathrm{T}_{4}\right) \mathrm{ng} / \mathrm{ml}$ & $91.980 \pm 15.466$ & $\begin{array}{c}114.550 \pm 14.088 \\
\# @ @ @\end{array}$ & $36.860 \pm 4.738$ & $\begin{array}{c}69.675 \pm 11.454 \\
@\end{array}$ \\
\hline Total triidothyronine $\left(\mathrm{T}_{2}\right) \mathrm{ng} / \mathrm{ml}$ & $3.0566 \pm 0.315$ & $3.0514 \pm 0.112$ & $3.558 \pm 0.432$ & $3.343 \pm 0.124$ \\
\hline $\mathrm{T}_{3} / \mathrm{T}_{4}$ ratio & $0.0359 \pm 0.004$ & $0.0281 \pm 0.003$ & $\begin{array}{c}0.102 \pm 0.015 \\
\# \# \# @ @ @\end{array}$ & $0.0527 \pm 0.009$ \\
\hline Thyroid weight (gm) & $0.210 \pm 0.020$ & $0.160 \pm 0.010$ & $0.170 \pm 0.020$ & $0.140 \pm 0.010 \#$ \\
\hline TBARS (nmol of MDA formed/mg of thyroid tissue & $6.723 \pm 1.480$ & $5.120 \pm 0.435$ & 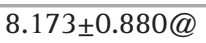 & $6.078 \pm 0.740$ \\
\hline GSH (Micromol/gram of thyroid tissue) & $7.187 \pm 0.992$ & $2.333 \pm 0.515 \# \#$ & $2.707 \pm 0.405 \# \#$ & $\begin{array}{c}5.087 \pm 0.673 \\
@\end{array}$ \\
\hline \multicolumn{5}{|c|}{$\begin{array}{l}\text { For serum analysis the values are expressed as mean SEM, }(n=5) \text { analyzed using One-way ANOVA followed by Dunnett's } \\
\text { Multiple Comparison Test. For tissue parameters the values are expressed as mean SEM, ( } n=3) \text {, analyzed using One-way } \\
\text { ANOVA followed by Dunnett's Multiple Comparison Test ( } \# p<0.05 \text { vs PTU+VEH; @ }<<0.05 \text { vs PTU+STD). }\end{array}$} \\
\hline
\end{tabular}

Animals: Adult Swiss Albino female mice (3-5 months; 25-35 gm) were procured from Panacea Biotec Ltd, Lalru India and were housed in polypropylene cage under standard laboratory conditions as per CPCSEA guidelines. They were fed with standard pellet diet (Shree Jagdambey Feed Industries, Moga, Punjab) and water ad libitum. The experimental study was duly approved by the Institutional Animal Ethics Committee (IAEC) [IAECCTIPS/2015/VII/0042 (PCL-M)].

Preparation and phytochemical screening of Crataeva nurvula plant extract: The dried stem bark of Crataeva nurvula $(3.5 \mathrm{Kg})$ was procured from Herbal Health Research Consortium Pvt. Ltd. Amritsar duly certified on basis of description and physico-chemical parameters (Lot No. VRN-024, Certificate of Analysis A. R. No. 06/2015/
IH/086, in compliance with Q.S.I.M.P. Volume 10, Page no. 106-108). It was further authenticated by Singh, Chief Scientist Herbology, Aimil Pharmaceuticals (India) Limited, New Delhi. A voucher (HHRC/RT/0416/15-16) and plant specimen was submitted to Pharmacology department of our college for future reference. The CN bark extract was prepared using repeated maceration technique and screened for presence of phytochemicals as per the method described in (Kaur et al. 2017).

Experimental design: The experimental hypothyroidism was induced in adult female Swiss Albino Mice (2535 gms) using, 6-Propyl-3-thiouracil (PTU), an antithyroid drug (10 $\mathrm{mg} / \mathrm{kg} /$ day by oral gavage for 15 days) (Panda and Kar, 2005). The experiment was of 37 days including 7 day acclimatization of animals to laboratory 
environment. Figure 1 shows that the protocol involved, induction of hypothyroidism for first 15 days using PTU and treatment for the next 15 days with vehicle (VEH) only, standard (STD) drug and test (CN 400 and CN 600) drug respectively).

Figure 1: The Experimental design

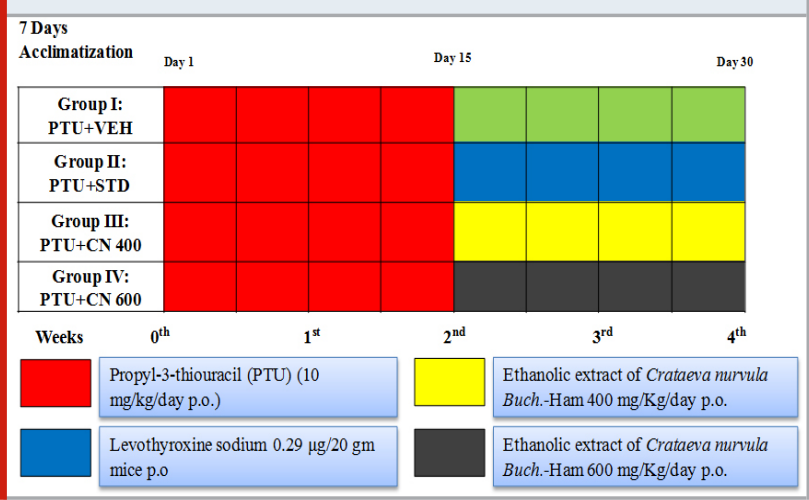

Serum triidothyronine $\left(T_{3}\right)$ and thyroxine $\left(T_{4}\right)$ levels: Blood was withdrawn 24 hours after the last dose on day 30th via retro-orbital method. The blood samples were centrifuged for $20 \mathrm{~min}$ (2000 rpm) to separate the serum which was stored at $-200 \mathrm{C}$ for further biochemical investigations. The serum $\mathrm{T}_{3}$ and $\mathrm{T}_{4}$ levels were determined using the commercially available ELISA thyrokit (ERBA Lachema s.r.o., Czech Republic) on Day 30th. The estimation was based on direct solid phase competitive enzyme immunoassay and the results were expressed in $\mathrm{ng} / \mathrm{ml}$.

Thyroid gland oxidative stress parameters: The thyroid gland was perfused with ice-cold 0.85\% Sodium chloride solution was isolated, weighed and placed in 1.15\% potassium chloride solution (in the ratio of $1 \mathrm{gm}$ wet tissue to $9 \mathrm{ml}$ of $1.15 \%$ potassium chloride). It was then homogenized in tissue homogenizer. An aliquot of $10 \%$ $\mathrm{w} / \mathrm{v}$ homogenate was preserved at $-20 \mathrm{oC}$ for estimating MDA (TBARS) and reduced glutathione (GSH) levels. TBARS assay values were reported as malondialdehyde (MDA) equivalents, which is a secondary by product of lipid peroxidation. The reaction of a 2-thiobarbituric acid (TBA, chromogenic reagent), with MDA at $25^{\circ} \mathrm{C}$ at $\mathrm{pH} 4$ gives rise to red colouration, which when extracted in organic layer was determined photometrically at $532 \mathrm{~nm}$ (Ohkawa et al. 1979).

To the 10\% w/v homogenate, added 5\% trichloroacetic acid (TCA), in order to precipitate the protein hydrolysates. The mixture was incubated for $10-15 \mathrm{~min}$ at $2-8{ }^{\circ} \mathrm{C}$, and centrifuged (5000 rpm, $10 \mathrm{~min}$ ). The supernatant was then added to potassium phosphate buffer, $0.1 \mathrm{M} \mathrm{(pH} \mathrm{8.0)} \mathrm{and}$ 5,5'- dithiobis-2-nitrobenzoic acid (DTNB reagent; $4 \mathrm{mg} /$ $\mathrm{ml}$ in KPB, 0.1 M, pH 7.0). Reaction with DTNB reagent gave a yellow colored product that developed rapidly (2 min) and read at $412 \mathrm{~nm}$ (Ellman, 1959).
Body weight, food intake and water intake: Parameters like body weight, food intake, and water intake were recorded daily over the study duration and weekly average values were calculated.

Histopathological studies: The thyroid gland was excised, rinsed, and preserved in formaldehyde solution till histopathological studies of thyroid gland were done by hematoxylin and eosin staining (HEE) method (Sayaki and Azure, 1955). The histopathology images depicted the cell nuclei in blue color, blood vessels in red color, and other connective tissue with cytoplasm in shades of pink.

Statistical analysis: The values of biochemical estimation i.e. thyroid hormone $(n=5)$ and oxidative stress parameters in thyroid tissue $(n=3)$ are expressed as mean \pm SEM, analyzed using One-way ANOVA followed by Dunnett's Multiple Comparison Test. Physiological parameters are expressed as mean SEM $(\mathrm{n}=6)$, analyzed using Two-way RM ANOVA followed by Bonferroni post test to compare replicate means by row ( ${ }^{*} \mathrm{p}<0.05$ vs VEH; $\# \mathrm{p}<0.05$ vs PTU+VEH; @ $\mathrm{p}<0.05$ vs PTU+STD).

\section{RESULTS AND DISCUSSION}

Serum triidothyronine $\left(T_{3}\right)$ and thyroxine $\left(T_{4}\right)$ levels: Table 1 , shows that serum total $\mathrm{T}_{4}$ levels were significantly high in standard group in comparison with low and high dose treatment group, at Day 30th. Low dose treatment group had the significantly lower levels of $\mathrm{T}_{4}(\# \mathrm{p}<0.05)$. There were no significant changes in $\mathrm{T}_{3}$ levels, however, calculated $\mathrm{T}_{3} / \mathrm{T}_{4}$ ratio was found to be highest in low dose treatment group followed by high dose treatment group in comparison with standard group.

Studies reveal that fraction of both $\mathrm{T}_{4}$ and $\mathrm{T}_{3}$ is bound to mainly two proteins i.e. Thyroxine binding protein (TBG), Thyroxine binding prealbumin (TBPA) and albumin. T4 is 99.95\% bound to plasma proteins and its values are useful for diagnosis of hypothyriodism and hyperthyroidism (Wills \&t Harvard, 1983). Also, TBG levels are reported to be high in PTU-treated rats than LT4 treated rats that regulate levels of $\mathrm{T}_{4}$ in serum (Savu et al. 1989). In our study, low levels of $\mathrm{T}_{4}^{4}$ could be attributed to high levels of TBG in serum of treatment group mice. About 13\% of $\mathrm{T}_{3}$ is secreted at thyroidal level but majority is formed by peripheral monodeiodination via Type I 5’idothyronine monodeiodinase (DIO1) (Bianco et al. 2002). However, any change in DIO1, i.e., inhibition or stimulation alters $\mathrm{T}_{3}$ concentration and $\mathrm{T}_{3} /$ $\mathrm{T}_{4}$ ratio (Visser et al. 1978). So the results indicate that treatment groups showed significant DI01 stimulatory activity over standard group.

Oxidative stress parameters: Table 1 shows that the weight of thyroid gland was found to be significantly raised in disease control at Day $30^{\text {th }}$. the level of TBARS in thyroid gland was found to be raised in low dose treatment group with significant decrease in GSH levels of standard and treatment groups in comparison with disease control (@ $\mathrm{p}<0.05)$. Previous studies in hypthyroid/hypometabolic 
state and hyperthyroid/hypermetabolic state concluded that both conditions raised malondialdehyde levels due to altered antioxidant status (generation of $\mathrm{H}_{2} \mathrm{O}_{2}$ and ROS) and cholesterol profile (Torun et al. 2009; Halliwell and Gutteridge, 1990; Venditti \& Di Meo, 2006). Hydrogen peroxide is the main element that is used by thyroid peroxidase (TP0) for thyroid hormone biosynthesis (Weber et al. 2013) whereas PTU significantly inhibit $\mathrm{H}_{2} \mathrm{O}_{2}$ production and bring perturbances in cholesterol levels, thus acting as powerful antithyroid agent with strong antioxidant activity (Imamure et al.1986; Kaur et al. 2017) but LT therapy alone is not effective in reducing PTU induced oxidative stress associated with perturbation in lipid profile in preclinical rodent brain studies (Pan et al. 2013; Bhanja \&t Chainy, 2010). This is in correlation of our study in which disease control group showed lower MDA and raised GSH levels in contrast with standard and treatment groups due to its self antioxidant nature of PTU. Also, this must be discussed on the basis that with the increase in thyroid hormones, there is an increased GSH consumption to combat oxidative stress that can result in its lower levels as seen in treatment groups (Adali et al. 1999).

Body weight, food intake and water intake: Figure 2 shows that the water intake in mice was found to be significantly less in disease control, as compared to standard and treatment groups whereas water intake improved significantly from second week after standard and treatment drug administration. No significant change in food intake was observed in treatment duration. Body weight significantly increased in disease control during two weeks treatment duration whereas it was significantly less in standard group.

Figure 2: Physiological changes in PTU induced hypothyroid and $\mathrm{CN}$ treated mice.

Values are expressed as mean SEM $(\mathrm{n}=7)$, analyzed using Two-way RM ANOVA followed by Bonferroni post test to

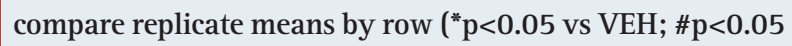
vs PTU+VEH; @ $<<0.05$ vs PTU+STD).

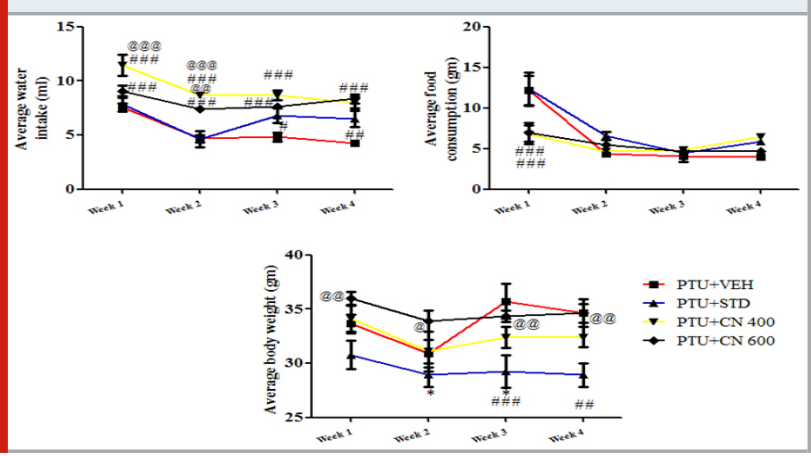

Thyroid hormones and pattern of food consumption are interrelated. Higgs et al. 1979 demonstrated that the administration of $\mathrm{LT}_{4}$ improves the food consumption whereas decrease food intake is observed in hypothyroid conditions with increase in central obesity (unpublished data) (Decuypere et al. 1987; Singh et al. 1971; Bhaskar et al. 2009). However no change in appetite is seen in our two weeks treatment duration of study. Choi et al. 2002 reported that thyrotropin releasing hormone (TRH) that stimulate thyroid hormone secreation via stimulation of hypothalamic pitiutary axis (HPA), increase water consumption in rats whereas the reverse is true in absence of thyroid hormones i.e. hypothyroidism and improvement in water intake is seen in our results of treatment groups and standard group. Varied results are reported regarding body weight change and thyroid conditions i.e. body weight increses with increase in TSH and decreases vice versa (Bray et al. 1976; Fox et al. 2008) and this is evident from our study results.

Histopathology: Figure 3 shows that the disease control group, depicted the scattered appearance and reduction in number of follicles and follicular cells with formation of vacuoles. The epithelial structure was seen lost with reduced colloid volume, however the cluster of C-cells were visible. The standard group had the presence of uniformly distributed follicular cells with cuboidal epithelium, intact cluster of C-cells, capillaries with reduced but visible colloid volume and appearance of vacuolization. The low dose treatment group had the presence of epithelium around follicular cells with some follicles partially filled and some devoid of colloidal material. However, blood capillaries and C-cells are visible with adequate number of follicles. The thyroid gland of high dose treatment group had the bunch of follicles rich in colloidal material with abundant follicular cells, C-Cells and embedded capillaries. However, low degree of vacuolization is also observed.

Figure 3: Histpathological and structural changes in PTU induced hypothyroid and $\mathrm{CN}$ treated mice thyroid gland $\mathrm{A}$ ) PTU+VEH; B) PTU+STD; C) PTU+CN 400 and D) PTU+CN 600 group.

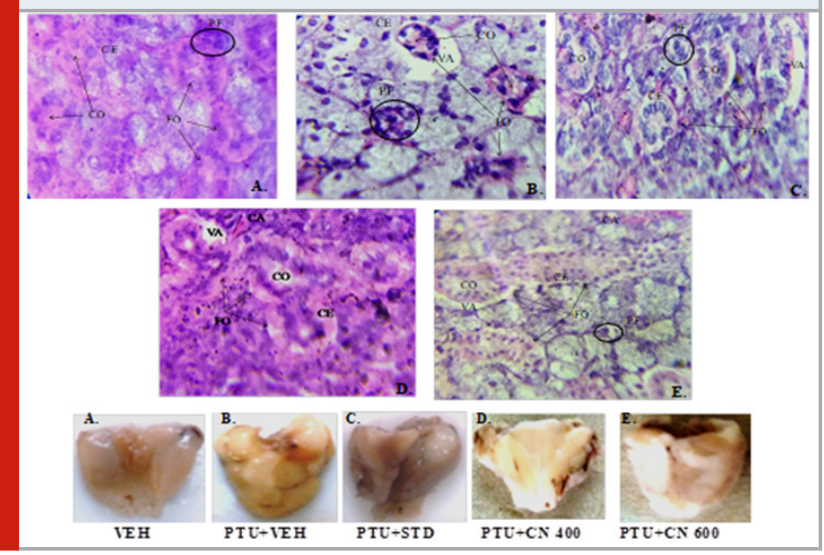

Petrova et al. 2014, demonstrated that the administration of $\mathrm{LT}_{4}$ or increase in thyroid hormones is characterized by presence of large size follicles, availability of more colloid, reduction in resorptive vacuoles with flattened follicular epithelium. Also Rajab et al. 2015 demonstrated that the supranormal levels of thyroid hormones distort the morphology of gland characterized by distention of lumen of follicles, reduction in thyrocyte height, follicular remodelling (fusion) and thyrocyte death due to lack of trophic effect and cytoprotection offered by 
thyroid stimulating hormone. This supports somewhat distorted structure observed in the histology of treatment groups. However, the improved cellular structure is seen in standard and treatment groups as compared to the disease control group.

\section{CONCLUSION}

The ethanolic extract of Crataeva nurvala is able to raise the thyroidal and extra-thyroidal conversion of T4 to T3 via enhanced activity of DI01, improved water intake and thyroid gland histology as compared to the standard therapy i.e. $\mathrm{LT}_{4}$. Genomic level study is required to understand the mechanistic intricacies of the Crataeva nurvala in treatment of thyroid disorders.

\section{REFERENCES}

Adali, M., Inal-erden, M., Akalin, A., \&t Efe, B. (1999). Effects of propylthiouracil, propranolol, and vitamin E on lipid peroxidation and antioxidant status in hyperthyroid patients. Clinical biochemistry, 32(5), 363-367.

Bhanja, S., \& Chainy, G. B. N. (2010). PTU-induced hypothyroidism modulates antioxidant defence status in the developing cerebellum. International Journal of Developmental Neuroscience, 28(3), 251-262.

Bhaskar, V. H., Profulla, K. M., Balakrishnan, B. R., Balakrishnan, N., \& Sangameswaran, B. (2009). Evaluation of the anti-fertility activity of stem bark of Crataeva nurvala buch-hum. African Journal of Biotechnology, 8(22).

Bianco, A. C., Salvatore, D., Gereben, B., Berry, M. J., \&t Larsen, P. R. (2002). Biochemistry, cellular and molecular biology, and physiological roles of the iodothyronine selenodeiodinases. Endocrine reviews, 23(1), 38-89.

Bianco, A. C., Salvatore, D., Gereben, B., Berry, M. J., \&t Larsen, P. R. (2002). Biochemistry, cellular and molecular biology, and physiological roles of the iodothyronine selenodeiodinases. Endocrine reviews, 23(1), 38-89.

Botella-Carretero, J. I., Gal, J. M., Caballero, C., Sancho, J., \&t Escobar-Morreale, H. F. (2003). Quality of life and psychometric functionality in patients with differentiated thyroid carcinoma. Endocrine-related cancer, 10(4), 601-610.

Bray, G., Fisher, D., \&t Chopra, I. (1976). Relation of thyroid hormones to body-weight. The Lancet, 307(7971), 1206-1208.

Choi, Y. H., Hartzell, D., Azain, M. J., \&t Baile, C. A. (2002). TRH decreases food intake and increases water intake and body temperature in rats. Physiology $\&$ behavior, 77(1), 1-4.

Decuypere, E., Buyse, J., Scanes, C. G., Huybrechts, L., \& Kühn, E. R. (1987). Effects of hyper-or hypothyroid status on growth, adiposity and levels of growth hormone, somatomedin C and thyroid metabolism in broiler chickens. Reproduction Nutrition Dévelopement, 27(2B), 555-564.

Ellman, G. L. (1959). Tissue sulfhydryl groups. Archives of biochemistry and biophysics, 82(1), 70-77.

Fox, C. S., Pencina, M. J., D’Agostino, R. B., Murabito, J. M., Seely, E. W., Pearce, E. N., \& Vasan, R. S. (2008). Relations of thyroid function to body weight: crosssectional and longitudinal observations in a communitybased sample. Archives of internal medicine, 168(6), 587-592.

Garber, J. R., Cobin, R. H., Gharib, H., Hennessey, J. V., Klein, I., Mechanick, J. I., \& Woeber for the American Association of Clinical Endocrinologists and American Thyroid Association Taskforce on Hypothyroidism in Adults, K. A. (2012). Clinical practice guidelines for hypothyroidism in adults: cosponsored by the American Association of Clinical Endocrinologists and the American Thyroid Association. Thyroid, 22(12), 12001235.

Gutteridge, J. M. C. (1990). Role of free radicals and catalytic metal ions in human disease: an overview. Methods in Enzymology, 186, 1-85.

Higgs, D. A., Fagerlund, U. H. M., McBride, J. R., \&t Eales, J. G. (1979). Influence of orally administered L-thyroxine or 3, 5, 3'-triiodo-L-thyronine on growth, food consumption, and food conversion of underyearling coho salmon (Oncorhynchus kisutch). Canadian Journal of Zoology, 57(10), 1974-1979.

Imamure, M., Aoki, N., Saito, T., Ohno, Y., Maruyama, Y., Yamaguchi, J., \& Yamamoto, T. (1986). Inhibitory effects of antithyroid drugs on oxygen radical formation in human neutrophils. European Journal of Endocrinology, 112(2), 210-216.

Kaur, A., \&t Verma, S. K. (2018). Mechanistic role of Varuna (Crataeva nurvala) extract on thyroid gland and its histology through iodothyronine deiodinases. Asian J Pharm Clin Res, 11(10), 298-302.

Kaur, A., Khurana, N., \&t Verma, S. K. (2017). Potential thyrotropic and antihypercholesteronemic activity exhibited by ethanolic extract of Crataeva nurvala bark. Journal of Applied Pharmaceutical Science, 7(11), 069073.

Kaur, A., Verma, S. K., \&t Kalsi, S. (2016). Hypothyroidism: Management Based On Ayurvedic and Modern Therapeutic Perspective. International Journal of Pharmaceutics and Drug Analysis, 281-288.

Khare, C. P. (2008). Indian medicinal plants: an illustrated dictionary. Springer Science \& Business Media; 177

Khattar, V., \&t Wal, A. (2012). Utilities of Crataeva nurvala. International Journal of Pharmacy and Pharmaceutical Sciences, 4(4), 21-26.

Moriyama, K., Tagami, T., Usui, T., Naruse, M., Nambu, T., Hataya, Y., \&t Nakao, K. (2007). Antithyroid drugs inhibit thyroid hormone receptor-mediated transcription. The Journal of Clinical Endocrinology \& Metabolism, 92(3), 1066-1072.

Narayana, A., \&t Subhose, V. (2005). Standardization of Ayurvedic formulations: a scientific review. Bulletin of the Indian Institute of History of Medicine (Hyderabad), 
35(1), 21-32.

Ohkawa, H., Ohishi, N., \&t Yagi, K. (1979). Assay for lipid peroxides in animal tissues by thiobarbituric acid reaction. Analytical biochemistry, 95(2), 351-358.

Pan, T., Zhong, M., Zhong, X., Zhang, Y., \& Zhu, D. (2013). Levothyroxine replacement therapy with vitamin E supplementation prevents oxidative stress and cognitive deficit in experimental hypothyroidism. Endocrine, 43(2), 434-439.

Panda, S., \& Kar, A. (2005). Guggulu (Commiphora mukul) potentially ameliorates hypothyroidism in female mice. Phytotherapy Research: An International Journal Devoted to Pharmacological and Toxicological Evaluation of Natural Product Derivatives, 19(1), 7880.

Petersen, K., Bengtsson, C., Lapidus, L., Lindstedt, G., \&t Nyström, E. (1990). Morbidity, mortality, and quality of life for patients treated with levothyroxine. Archives of internal medicine, 150(10), 2077-2081.

Petrova, I., Mitevska, E., Gerasimovska, Z., Milenkova, L., \& Kostovska, N. (2014). Histological structure of the thyroid gland in apolipoprotein E deficient female mice after levothyroxine application. Pril (Makedon Akad Nauk Umet Odd Med Nauki), 35(3), 135-40.

Rajab, N. M. A., Ukropina, M., \&t Cakic-Milosevic, M. (2017). Histological and ultrastructural alterations of rat thyroid gland after short-term treatment with high doses of thyroid hormones. Saudi journal of biological sciences, 24(6), 1117-1125.

Razvi, S., Weaver, J. U., Butler, T. J., \& Pearce, S. H. (2012). Levothyroxine treatment of subclinical hypothyroidism, fatal and nonfatal cardiovascular events, and mortality. Archives of internal medicine, 172(10), 811-817.

Saravanan, P., Chau, W. F., Roberts, N., Vedhara, K., Greenwood, R., \&t Dayan, C. M. (2002). Psychological well-being in patients on 'adequate'doses of l-thyroxine: results of a large, controlled community-based questionnaire study. Clinical endocrinology, 57(5), 577585.

Savu, L., Vranckx, R., Maya, M., Gripois, D., Blouquit, M. F., \& Nunez, E. A. (1989). Thyroxine-binding globulin and thyroxine-binding prealbumin in hypothyroid and hyperthyroid developing rats. Biochimica et Biophysica Acta (BBA)-General Subjects, 992(3), 379-384.

Sayaki, H., \&t Azure, B. (1955). Counterstain in the immunohistochemical evaluation of heavily pigmented nevomelanocytic lesion. Appl Immunohistochem, 3, 268-71.

Schneider, R., Schneider, M., Reiners, C., \& Schneider, P. (2012). Effects of levothyroxine on bone mineral density, muscle force, and bone turnover markers: a cohort study. The Journal of Clinical Endocrinology $\mathrm{At}$ Metabolism, 97(11), 3926-3934.

Singh, D. V., Anderson, R. R., \&t Turner, C. W. (1971). Effect of decreased dietary protein on the rate of thyroid hormone secretion and food consumption in rats. Journal of Endocrinology, 50(3), 445-450.

Torun, A. N., Kulaksizoglu, S., Kulaksizoglu, M., Pamuk, B. O., Isbilen, E., \&t Tutuncu, N. B. (2009). Serum total antioxidant status and lipid peroxidation marker malondialdehyde levels in overt and subclinical hypothyroidism. Clinical endocrinology, 70(3), 469474.

Venditti, P., \&t Di Meo, S. (2006). Thyroid hormoneinduced oxidative stress. Cellular and Molecular Life Sciences CMLS, 63(4), 414-434.

Visser, T. J., Lamberts, S. W. J., Wilson, J. H. P., Docter, R., \& Hennemann, G. (1978). Serum thyroid hormone concentrations during prolonged reduction of dietary intake. Metabolism, 27(4), 405-409.

Weber, G., Rabbiosi, S., Zamproni, I., \&t Fugazzola, L. (2013). Genetic defects of hydrogen peroxide generation in the thyroid gland. Journal of endocrinological investigation, 36(4), 261-266.

Wills, M. R., \&t Havard, B. (2013). Laboratory investigation of endocrine disorders. Butterworth-Heinemann. 